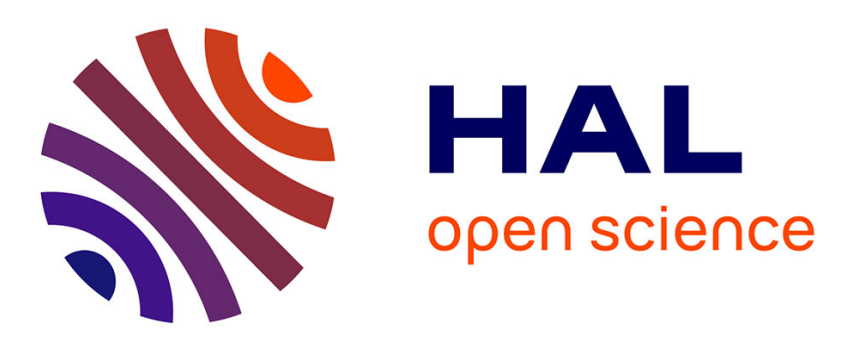

\title{
Variability of the mechanical properties of hemp concrete
}

\author{
César Niyigena, Sofiane Amziane, Alaa Chateauneuf, Laurent Arnaud, \\ Laetitia Bessette, Florence Collet, Christophe Lanos, Gilles Escadeillas, Mike \\ Lawrence, Camille Magniont, et al.
}

\section{To cite this version:}

César Niyigena, Sofiane Amziane, Alaa Chateauneuf, Laurent Arnaud, Laetitia Bessette, et al.. Variability of the mechanical properties of hemp concrete. Materials Today Communications, 2016, 7, pp.122-133. 10.1016/j.mtcomm.2016.03.003 . hal-01302340

\section{HAL Id: hal-01302340 \\ https://hal-univ-rennes1.archives-ouvertes.fr/hal-01302340}

Submitted on 8 Jun 2016

HAL is a multi-disciplinary open access archive for the deposit and dissemination of scientific research documents, whether they are published or not. The documents may come from teaching and research institutions in France or abroad, or from public or private research centers.
L'archive ouverte pluridisciplinaire HAL, est destinée au dépôt et à la diffusion de documents scientifiques de niveau recherche, publiés ou non, émanant des établissements d'enseignement et de recherche français ou étrangers, des laboratoires publics ou privés. 


\section{Highlights}

This study is focused on statistical analysis of hemp concrete properties.

The main objective is to determine statistically the variability of the three main properties, which are: material density, compressive strength and Young's modulus.

Two types of hemp shiv have been used with two batches for each type.

Three probability distributions, namely: normal, log-normal and Weibull, have been proposed to fit the experimental results.

There is an accurate repeatability for compressive strength and dry density

The results for Young's modulus are of a large variability.

The mixing procedure must be done with an utmost care.

The impact of initial water content on the density has been also highlighted.

The hemp with small particle sizes leads to better mechanical properties of hemp concrete. 


\title{
Variability of the mechanical properties of hemp concrete
}

\author{
César Niyigena $^{1}$; Sofiane Amziane ${ }^{1 *}$; Alaa Chateauneuf ${ }^{1}$, \\ Laurent Arnaud $^{\left(2^{*}\right)}$, Laetitia Bessette ${ }^{(3)}$, Florence Collet ${ }^{(4)}$, Christophe Lanos ${ }^{(4)}$, Gilles \\ Escadeillas $^{(5)}$, Mike Lawrence ${ }^{(6)}$, Camille Magniont ${ }^{(5)}$, Sandrine Marceau ${ }^{(7)}$, Sara Pavia ${ }^{(8)}$, Ulrike \\ Peter ${ }^{(9)}$, Vincent Picandet ${ }^{(10)}$, Mohamed Sonebi ${ }^{(11)}$, Pete Walker ${ }^{(6)}$,
}

1 : Clermont université, Institut Pascal, Polytech' Clermont-Ferrand - 63174 Aubière Cédex, France

cesar.niyigena@univ-bpclermont.fr, alaa.chateauneuf@univ-bpclermont.fr

* Corresponding author and secretary of TC 236 BBM: sofiane.amziane@univ-bpclermont.fr

2: Chair, Ecole Nationale Supérieure d'Arts et Métiers, ENSAM Cluny, France,

laurent.arnaud@ensam.eu

3: Centre Technique Louis VICAT, L'Isle d'Abeau, France, L'Isle d'Abeau, laetitia.bessette@vicat.fr

4: LGCGM, Université Rennes 1, Rennes, France, florence.collet@univ-rennes1.fr, christophe.lanos@univrennes1.fr

5: Université de Toulouse, UPS, INSA, LMDC (Laboratoire Matériaux et Durabilité des Constructions), Toulouse, camille.magniont@insa-toulouse.fr, gilles.escadeillas@insatoulouse.fr

6:BRE Centre for Innovative Construction Materials, University of Bath, Bath, UK m.lawrence@bath.ac.uk, P.Walker@bath.ac.uk

7: Paris-Est, IFSTTAR, MAST, Marne-La-Vallée, France, sandrine.marceau@ifsttar.fr

8: Dept of Civil Engineering, Trinity College Dublin, Ireland, Pavias@tcd.ie

9: Lhoist, Lhoist Recherche et Développement S.A., Belgium, ulrike.peter@lhoist.com

10: Université de Bretagne Sud, 6 : EA 4250, LIMatB, F-56100 Lorient, France, vincent.picandet@univ-ubs.fr,

11: Queen's University Belfast, School of Planning, Architecture \& Civil Eng., Belfast, BT7 1NN, UK, m.sonebi@qub.ac.uk

\section{Abstract}

This study is focused on statistical analysis of hemp concrete properties. The main objective is to determine statistically the variability of the three main properties, which are: material density, compressive strength and Young's modulus. The analysis is done with respect to four main parameters, namely: the testing laboratory equipment and procedure, the hemp shiv type, the batch elaboration and finally the specimen size 
Two types of hemp shiv have been used with two batches for each type. Two cylindrical specimen sizes have been considered: $11 \times 22 \mathrm{~cm}$ and $16 \times 32 \mathrm{~cm}$. All the specimens were manufactured and dried in the same laboratory in order to ensure the repeatability and homogeneity of studied material. After 90 days of drying under ss same conditions, the specimens were transported to ten different laboratories for compressive testing. Before testing, a drying protocol during 48 hours was applied by all laboratories for all specimens. Then, a unique protocol for compressive testing has been applied using the compressive testing machine in each laboratory. Finally, all data have been collected for statistical analysis. In this study, the results obtained by different laboratories show low variability for compressive strength and dry density; which is not the case for Young's modulus. Three probability distributions, namely: normal, lognormal and Weibull, have been proposed to fit the experimental results.

\section{Introduction}

The use of plant origin aggregates is nowadays considered as an essential way in manufacturing environmentally friendly building materials. Many aggregates of this kind exist and are used in the construction industry, either in new structures or renovation of existing buildings, for example, aggregates of sunflower, hemp shiv...[1-3]. In contrast to aggreagtes of mineral origin, plant origin aggregates are renewable and carbon neutral materials. They also have other advantages such as good thermal and acoustic insulation properties. However, the major drawback is related to their low mechanical performance [4-6].

For more than one decade, the researches on these materials have not ceased to increase. A very recent study was conducted by Binici et al. [7] on the use of sunflower and waste cotton textiles for manufacturing insulation. Other researches have been also conducted on the use of the hemp shiv in insulation [8]. In the framework of the present study, the herein literature review focuses on concrete made from hemp shiv, and particularly on its mechanical behavior. 
Several parameters influence the mechanical properties of hemp concrete. Some are due to the nature of its constituents such as the aggregate size, the type of binders, and other parameters are due to manufacturing method, such as the compaction energy and the molding method $[9,10]$.

The density of hemp concrete is related to quality and quantity of constituents, the aggregate size, their porosity and the energy of compaction. Considering all these parameters, different and variable density values are found in the literature. In a study conducted by Cerezo [9], several formulations were tested and specimens between 12 and 29 were manufactured for each formulation. The density distribution of each formulation was homogenous with a coefficient of variation between $1.5 \%$ and $3.5 \%$.

For ten different formulations, Cerezo obtained the final average density values ranging from $256 \mathrm{~kg} / \mathrm{m}^{3}$ to $782 \mathrm{~kg} / \mathrm{m}^{3}$. Although she considers in her analysis that the series have a low dispersion, this is not true at all levels. This is only valid at the intra-formula level, but not for the inter-formula level, because in this latter case, considerable dispersion is observed for both final and initial mean values; which vary in the range of $455 \mathrm{~kg} / \mathrm{m}^{3}$ to $1140 \mathrm{~kg} / \mathrm{m}^{3}$.

In parallel, F. Collet [11] has determined the density of two kinds of hemp concrete (batch A for one hemp and $\mathrm{B}$ for another) by using three different methods: weighing and dimension measurement, pycnometer and mercury porosimeter. The first step of its study is to determine the representative elementary volume. The density variation obtained between the samples of 5 $\mathrm{cm}$ and $20 \mathrm{~cm}$ edges was of approximately 4\%. Thanks to this low variation in the average density between samples, she concluded that samples of $5 \mathrm{~cm}$ edge are representative of hemp concrete. However, the differences in results were observed with respect to the used measurement method. For the pycnometer test, the density for batch A is $390 \mathrm{~kg} / \mathrm{m}^{3}$ and $425 \mathrm{~kg} / \mathrm{m}^{3}$ for batch B. The test of mercury porosimeter gave a dry density of $609 \mathrm{~kg} / \mathrm{m}^{3}$ and $664 \mathrm{~kg} / \mathrm{m}^{3}$ for batches $\mathrm{A}$ and $\mathrm{B}$, respectively. With the method of weighing and measuring dimensions for two different series in batch A, she got $408 \mathrm{~kg} / \mathrm{m}^{3}$ and $406 \mathrm{~kg} / \mathrm{m}^{3}$ with $6.6 \%$ and $2.7 \%$ of coefficient of variation for the first and second series, respectively. Finally, in batch B, 
the mean value density for sample of $5 \mathrm{~cm}$ edge cube is $438 \mathrm{~kg} / \mathrm{m}^{3}$ with a standard deviation equal to $5.7 \%$.

Another study has been conducted by Nguyen [10] on two types of hemp shives: the first with pure shiv particles (CP), while the other one contains fibres (CF). It is shown that there is no difference between the two shives in terms of density. For specimens tested under the same conditions, the observed difference was less than $2 \%$. Results obtained were in the range of 450 $\mathrm{kg} / \mathrm{m}^{3}$ to $800 \mathrm{~kg} / \mathrm{m}^{3}$ at 90 days. This dispersion is mainly based on three main parameters of formulation and manufacturing process, namely the binder/aggregate ratio; the water/binder ratio and the compaction strength.

Nguyen [10] also highlighted parameters influencing the compressive strength. Because of the low rigidity of particles, hemp concrete has a very ductile behavior in both compression and tension. Based on test results, he obtained a compressive strength, for a strain equal to $7.5 \%$ after 28 days, which varies between 0.2 MPa and 3.6 MPa. On her side, Cerezo [9] obtained the compressive strength ranging between 0.25 and $1.15 \mathrm{MPa}$. For low binder content, the compressive strength is around 0.25 MPa. For intermediate dosage, it varies between 0.4 and 0.8 $\mathrm{MPa}$ and for high binder content, it is $1.15 \mathrm{MPa}$. She concluded that mechanically, hemp concrete is characterized by an elastic-plastic behavior, and that this material must be used with a support structure to meet structural requirements.

Other parameters may also influence the mechanical behavior of hemp concrete such as drying conditions, the age of hemp concrete and the size of hemp particles [12]. Taking into account these parameters, Arnaud and Gourlay [12] obtained compressive strength, which varies between 0.35 MPa and 0.85 MPa for the age of 21 days to 24 months. Increasing the energy of compaction during the manufacturing process may enhance the maximum compressive strength. However it has been proven that the compressive strength is limited to $3 \mathrm{MPa}$ for a compaction pressure between 0.6 MPa and $1 \mathrm{MPa}$ [13]. Nguyen [10] obtained a compressive strength beyond 
3.5 MPa at 28 days by using a compaction stress maintained during 48 hours before demoulding the hemp concrete fresh paste.

Young's modulus values found in the literature have also high variability and the methods used for its calculation are also different. According to Cerezo [9], the Young's modulus is defined as the slope at the origin of the strength-strain curve by considering the validity of the small strain assumption. Young's modulus varies from 1 to $3 \mathrm{MPa}$ for low binder content; 32 to $95 \mathrm{MPa}$ for intermediate dosages and 100 to $160 \mathrm{MPa}$ for high dosage. For various formulations, Nguyen [10] obtained, at 90 days, the Young's modulus between $25 \mathrm{MPa}$ and $176 \mathrm{MPa}$; using pure hemp particles. According to its study, the Young's modulus of a given specimen is calculated based on the strongest increase in the ratio strength/strain recorded at the beginning of the loading stage.

The results in the literature show that the values for properties of hemp concrete have a great variability and are sensitive to many factors. The literature shows also that there is a lack on consideration of the accuracy of testing instruments used and the variability of results due to experimentations. For example at one hand, Mounanga et al. [14] studied the influence of the composition and method of implementation on the development of mechanical properties of hemp concrete. At the other hand an analysis of the variability on the self-compacting concrete was led by Almeida Filho et al. [15]. In this last study, in order to reduce the impact of statistical errors, they used results from 10 to 24 specimens for each type of formulation.

As other materials, the variability performance of hemp concrete has two origins: intrinsic variability of the studied material itself and uncertainty caused by insufficient information with respect to these mechanical performance [16]. It is of course fundamental, even though not necessarily easy, to distinguish between these two sources through appropriate statistical 
modeling. For this reason, a statistical study is required to assess the certainty and variability of the results for the mechanical properties of hemp concrete.

In the present study, a statistical analysis of the results taking into account two types of hemp shives, four types of batches, and two specimen sizes, is carried out in order to define the probability distributions fitting the experimental results. The considered characteristics are: density, maximum compressive strength and Young's modulus. The mechanical compression tests were conducted in ten different laboratories, which allows us to analyze the impact of the laboratory on the estimation of material characteristics.

\section{Material and methods}

The specimens in this study, were manufactured using two hemp shives with the same binder, prompt natural cement (PNC) and citric acid. The characterization results for bulk density, water absorption and particle size distribution, are given for both shives in section 3.1. The protocols and methods related to manufacturing, mixing process and compressive testing are given in section 3.2. The compressive tests have been made using different machines under the same protocol, and the experimental results were collected for statistical analysis. The considered parameters during the mixing and manufacturing process are provided in Table 1.

\begin{tabular}{|c|c|c|c|c|c|c|c|c|c|c|}
\hline \multirow{2}{*}{\multicolumn{2}{|c|}{$\begin{array}{l}\text { Specimen sizes } \\
\text { Type of batch }\end{array}$}} & \multicolumn{4}{|c|}{ Specimen $11 \mathrm{cmX} 22 \mathrm{~cm}$} & \multicolumn{4}{|c|}{ Specimen $16 \mathrm{cmX} 32 \mathrm{~cm}$} & \multirow{2}{*}{$\begin{array}{l}\text { Total per } \\
\text { laboratoire }\end{array}$} \\
\hline & & I & II & III & IV & I & II & III & IV & \\
\hline \multirow{10}{*}{ 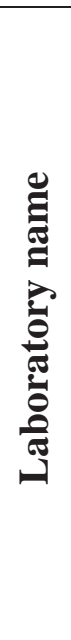 } & Institut Pascal (A) & & 3 & & 3 & & 3 & & & 9 \\
\hline & Belfast (B) & & 2 & 2 & & & & & & 4 \\
\hline & Trinity (C) & 2 & & & 2 & & & & & 4 \\
\hline & LMDC Toulouse (D) & 2 & & 2 & & & & & & 4 \\
\hline & Bath univ (E) & & 3 & & 3 & & & & & 6 \\
\hline & LGCGM Rennes (F) & & 3 & & 3 & & & & 3 & 9 \\
\hline & Vicat (G) & 3 & 1 & 6 & & & & 3 & & 13 \\
\hline & IFSTTAR (H) & & 3 & & 4 & & & & & 7 \\
\hline & LiMATB Lorient (I) & 3 & & 3 & & 3 & & & & 9 \\
\hline & Lhoist (J) & 2 & & 2 & & & & & & 4 \\
\hline
\end{tabular}




\begin{tabular}{|l|c|c|c|c|c|c|c|c|c|}
\hline Total per batch & 12 & 15 & 15 & 15 & 3 & 3 & 3 & 3 & 69 \\
\cline { 1 - 4 } Total per specimen size & \multicolumn{6}{|c|}{57} & \multicolumn{7}{|c|}{12} \\
\hline
\end{tabular}

Table 1 : Summary datas for tested specimens

\subsection{Raw material characterization}

\subsubsection{Shives}

The shives used in this study are from the same producer, but they were stored in two separate places. One bag with the reference 130173 KANABAT at the ENTPE laboratory, noted S1 shiv, and the other one at Vicat laboratory with the reference 130174 KANABAT, noted S2 shiv. Samples, of about $1 \mathrm{~kg}$ each, have been taken and characterization tests were conducted according to the protocol proposed in $[17,18]$. The characterization tests were made in laboratories A and G; they include among others: bulk density, water absorption and particle size distribution by two methods: mechanical sieving and image analysis.

\subsubsection{Bulk density $\left(\mathrm{kg} / \mathrm{m}^{3}\right)$}

Tests of bulk density were conducted according to the protocol in [18]. The results obtained for the two types of hemp shives show that there is slight difference, with $143.6 \mathrm{~kg} / \mathrm{m}^{3}$ for $\mathrm{S} 1$ and $147.5 \mathrm{~kg} / \mathrm{m}^{3}$ for $\mathrm{S} 2$. Observed differences may be due to errors in manual handling or to the accuracy of the used method. Whatever, these differences are acceptable as they are below 2.7\%.

\subsubsection{Water absorption}

Tests of water absorption were conducted according to the protocol in [17]. The water absorption capacity of these aggregates are determined gravimetrically by applying the expression: $W(t)=$ $\frac{M(t)-M_{0}}{M_{0}} \times 100$, where $W(t)$ is the water absorption ratio at time $t, M(t)$ the soaked hemp shive aggregate mass at time $t$, and $M_{0}$ is the initial oven-dried aggregate mass. The water absorption $W$ is calculated after soaking for 48 hours using the expression: $W=I R A+K_{1} \times \log (t)$, where $K_{1}$ is a kind of diffusion rate in shiv cells. IRA represents the characteristic factor of the 
external water adsorption on the shiv surface, and is related to the first minute measurement. The results are shown in Figure 1.
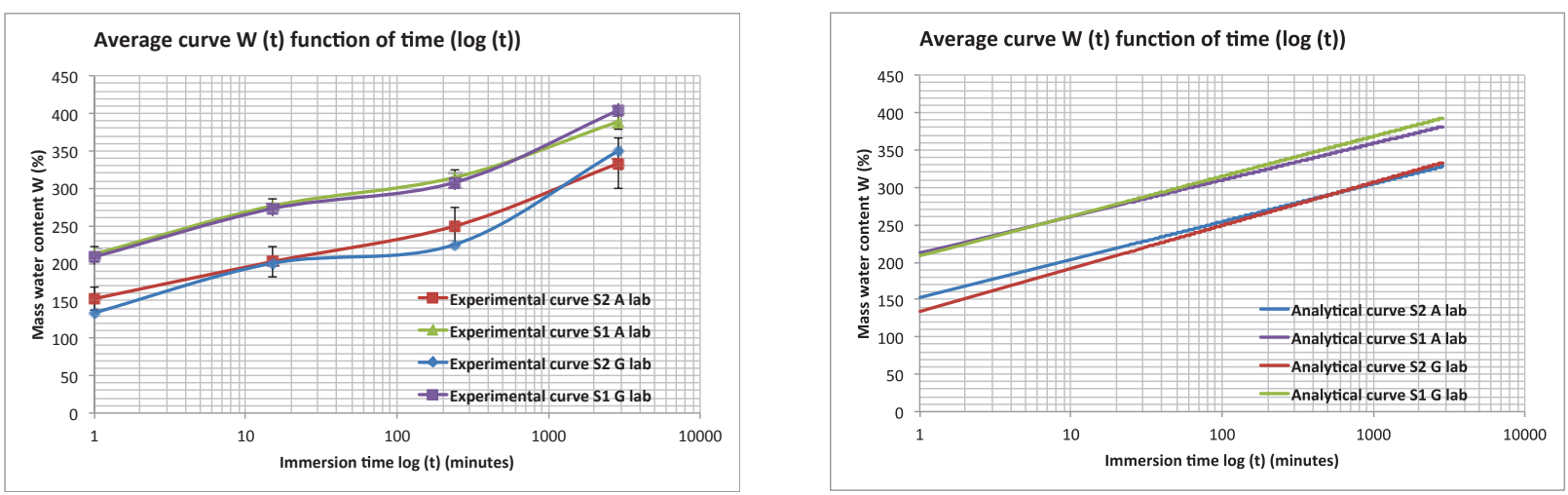

Figure 1: Water absorption curves (experimental and analytical) for S1 and S2, immersion time in log scale

For comparison purpose, the test was conducted in two separate laboratories: A and G. The results are almost identical for both laboratories especially for initial mass water absorption but with a slight difference in the case of S2. In terms of initial water absorption, they are different, with initial mass water absorption around $150 \%$ and $200 \%$ for S2 and S1, respectively.

\subsubsection{Particle size distribution}

The particle size distributions are analyzed by using two methods: mechanical sieving and image analysis. The first method is the reference technique when dealing with characterization of mineral aggregates [19]. For the analysis of vegetal origin aggregates, square mesh sieves are of limited interest because they do not take into account the elongation of aggregates [20].

By the sieving method, Nozahic [21] made a comparative study on hemp shiv and sunflower aggragates and realized that the two types are almost similar in size. He concluded that mechanical sieving technique is not yet suitable neither for determining the size of a lignocellulosic particle aggregate, nor for comparison of two different kinds of aggregates. His conclusion is in accordance with the results of mechanical sieving obtained in the present study and shown in Figure 2 (a) where both S1 and S2 are almost identical. 


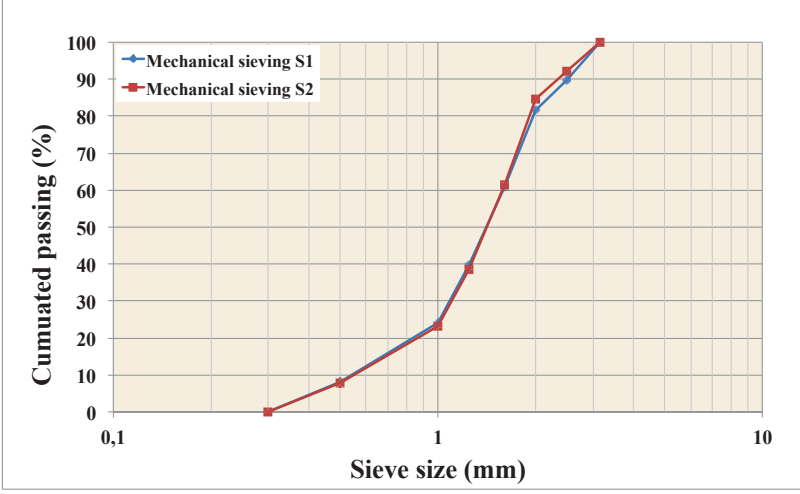

(a) Mechanical sieving method (S1 and S2)

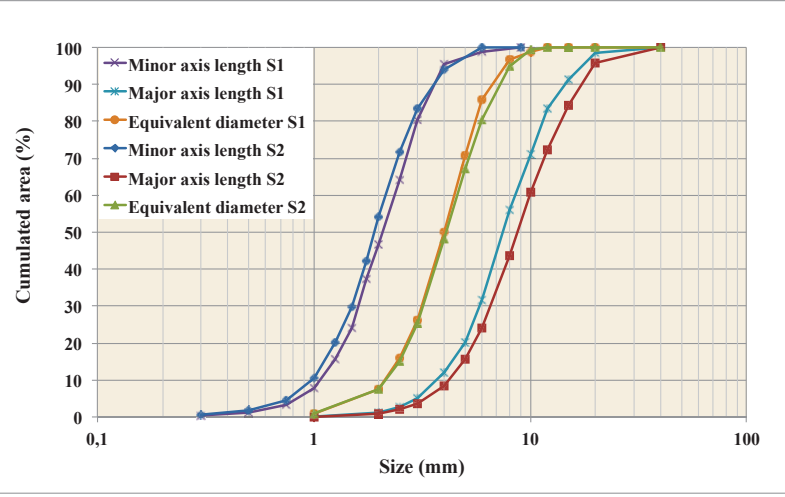

(b) Image analysis method (S1 and S 2)

Figure 2: Grading curve by mechanical and image analysis methods for S1 and S2.

However, the second method of image analysis brings clearly richer information than the previous method. This latter has been used and published for the first time in 1999 [22]. In our study, we have used a similar approach to the work in $[10,12,24]$ but with the ImageJ software [23]. The comparison of both S1 and S2, illustrated in Figure 2 (b), reveals, in contrast to sieving method, significant differences between both axes. The obtained specific areas are $13187 \mathrm{~mm}^{2}$ and $13913 \mathrm{~mm}^{2}$ for S2 and S1, respectively.

\subsection{Preparation of compression test specimens}

\subsubsection{Mix proportioning}

In construction, hemp concrete has several applications, such as: filling wooden frame walls, roofing insulation, etc. To each application correspond a given number of specifications such as minimum compressive strength and Young's modulus [25], which can be met by specific formulations. For the purpose of the herein study, it has been decided to use the formulation for wall application [25]; as the objective is not to analyse the formulation, any other one may have been used. The quantities in kilograms per batch of 80 liters are detailed in Table 2.

\begin{tabular}{|c|c|c|c|c|c|}
\hline Shiv (kg) & PNC (kg) & Citric Acid & Water (kg) & Ratio Water/PNC & Ratio Shiv/PNC \\
\hline 8 & 20 & 0.06 & 19,2 & 0.96 & 0.4 \\
\hline
\end{tabular}

Table 2: Tested formula for wall application per batch 


\subsubsection{Mixing of hemp concrete}

Each constituent is weighed in buckets. The shiv is put in the mixer, then the PNC with Citric Acid is introduced; they are then mixed with $40 \%$ of the mixing speed for few minutes. Water is added and the mixing retaining. The mixing speed is increased to 50\% then kept until homogeneous mixture is obtained. Finally, for the use, the mixer is emptied into a wheelbarrow.

\subsubsection{Casting method for specimens}

The mold is filled by 5 or 6 layers; two consecutive layers must be compacted using a suitable tool. For the last layer, the upper surface is kept smooth and the specimen is weighed. A cover is put and the specimen is kept returned for a period of at least 72 hours after which the cover and the bottom are removed. The specimen is then kept at $20^{\circ} \mathrm{C}$ and $55 \%$ of relative himidity for 90 days. To ensure that the tested specimens are identical, they were manufactured the same day and were dried for 90 days under the same conditions at the laboratory G. After this drying period, samples were transported to ten different laboratories for compression testing.

\subsubsection{Protocol of the compressive test}

Tests were done under the same conditions, the detailed below protocol, was carefully followed by all laboratories. Specimens were dried under an oven at $50^{\circ} \mathrm{C}$ for 48 hours before the compressive test.

1. Weighing the specimen with the mold; then remove the mold using a cutter: remove the sample ends then cut just the surface of the mold; and mark it with the same reference on the mold;

2. weighing the specimen without the mold; then put it in an oven at $50^{\circ} \mathrm{C}$ until a stabilization of weight equal to +/-2\%; and left it in a sealed plastic bag until the test day;

3. before the test, measure three diameters (at top, bottom and middle) and the height every $120^{\circ}$ 
4. no surfacing of the sample and a perfect parallel plates is made before the starting of the test;

5. The test must be displacement controlled at the rate of $3 \mathrm{~mm} / \mathrm{min}$ for loading stage. The unloading stage should be $6 \mathrm{~mm} / \mathrm{min}$ or free if it is not possible to control it;

6. Applying three load cycles depending on specimen size:

$\mathbf{1}^{\text {st }}$ cycle: loading is done from 0 to $1 \%$ of relative deformation and unloading until zero load or zero displacement; $2^{\text {nd }}$ and $3^{\text {rd }}$ cycles are the same as the $1^{\text {st }}$, the strain is always increased by $1 \%$ for each cycle. The final loading: from 0 until the total failure load of the specimen (maximum of $20 \%$ of strain) and unloading until zero load (when possible) or zero displacement.

Voluntarily for some specimens, in the case of lab C: I-11-7; I-11-8; IV-11-11; IV-11-12; and I lab: I-11-2; III-11-11; I-16-1; the compressive tests were done with a monotonic loading.

\subsection{Mechanical analysis of hemp concrete properties}

\subsubsection{Young's modulus (Floating modulus on loading stage)}

For the hemp concrete, the Young's modulus is not constant because of strong nonlinear behavior even in the elastic domain. As applied in soil mechanics [26], the hemp concrete may have also four different types of modulii, which can be calculated as shown in Figure 3. The initial tangent modulus $E_{\text {ini }}$ corresponds to the slope at the beginning of loading in the stressstrain curve. The various loading levels of the curve may be described by a "secant" modulus $E_{\text {sec }}$, defined by the slope of the line connecting the origin at the current point and a "tangent" modulus $E_{t a n}$, may be determined by the slope of the curve in the neighborhood of a given point. In cyclic loading, the modulus $E_{C Y C}$ may be determined by the slope of the line connecting the two points reversing the strain direction. In opposite to initial Young's modulus, which might have errors due to small strains, the tangent modulus calculated on loading phase with higher 
strain values, which allows reducing the errors. In our study, the modulus is calculated according to the procedure named "floating modulus".

\subsubsection{Young's modulus calculation method (floating modulus).}

According to the frequency of data acquisition (nearly $10 \mathrm{~Hz}$ or 10 values per second, Figure 4 ): the loading steps are identified then the floating modulus is calculated in each step using: $\mathrm{E}=\frac{\boldsymbol{\Delta \sigma}}{\boldsymbol{\Delta} \boldsymbol{\varepsilon}}$; where: $\mathrm{E}$ is the modulus around a given point, $\Delta \sigma$ and $\Delta \varepsilon$ are strength and strain respectively considered between -5 and +5 seconds around the considered point. The maximum of modulus is identified for each step. The floating Young's modulus value is therefore, the mean value of maximum values obtained at the $2^{\text {nd }} ; 3^{\text {rd }}$ and $4^{\text {th }}$ loading steps.

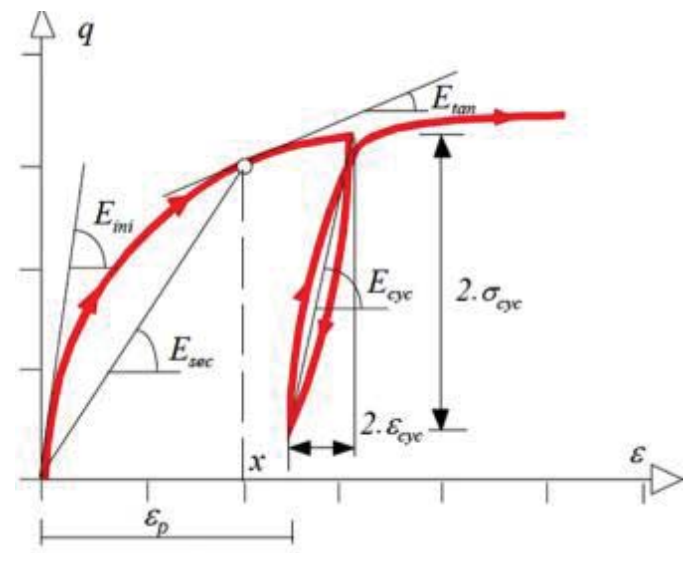

Figure 3: Modulus definitions [26]

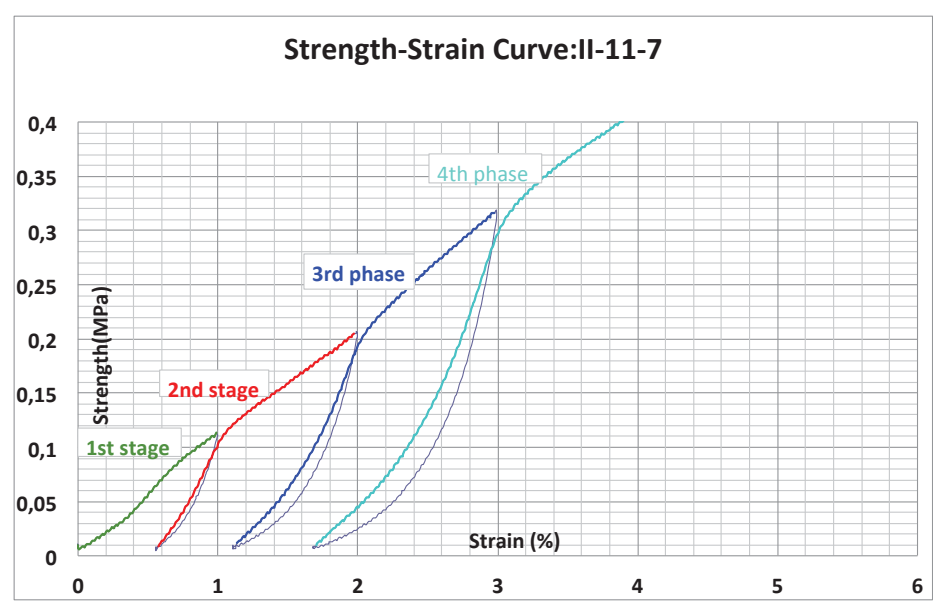

Figure 4 : Identification of the loading phases to calculate the floating modulus

\subsubsection{Characteristic values and Coefficient of variation (COV)}

The characteristic value of a quantity measured experimentally corresponds to the representative value to be included in the computation procedure for a purpose of design, maintenance or rehabilitation or any other decision process. For example, the compressive strength of concrete is defined as the resistance below which there are only $5 \%$ of test results [27]. Under the assumption of normality, it is proposed to calculate the characteristic value of concrete compressive strength as follows: $\mathrm{f}_{\mathrm{ck}}=\mathrm{f}_{\mathrm{cm}}-1.645 \sigma_{\mathrm{fc}}$ (1); where $\mathrm{f}_{\mathrm{ck}}$ is the characteristic value, 
$\mathrm{f}_{\mathrm{cm}}$ is the average value of all the test results and $\sigma_{\mathrm{fc}}$ is the standard deviation of test results; the coefficient 1.645 corresponds to a $5 \%$ quantile of the normal gaussain distribution. It is to note that all experimental results were subjected to the test of normality and the test was not rejected. Then formula in (1) is used in our study with the probability level of 5\%.

The coefficient of variation (COV) indicates the dispersion of the experimental results; it is calculated by the ratio between the Standard deviation and the mean value, in (\%). Table 3 gives accepted limits of standard deviation and coefficient of variation for concrete [15].

\begin{tabular}{lc}
\hline Quality control & Accepted limits for the coefficient of variation (\%) \\
\hline A (excellent) & 10 \\
B (average) & 15 \\
C (poor) & 20
\end{tabular}

Table 3: Accepted limits of variability of concrete compressive as a function of the quality control [15]

\subsubsection{Statistical tests}

According to the samples that we have, we can classify them in eight populations, four batches for both hemp shives and two specimen sizes in each batch. Using statistical tests, like Student test [28] by comparing samples two by two or ANOVA [29], we can determine whether the samples originate from the same population or not. ANOVA (ANalysis Of Variance) is a generalization of the mean comparison with $\mathrm{K}$ subpopulations or samples. $\mathrm{K}$ equal to 2 correspons to Student test. For ANOVA test, if the null hypothesis H0 is rejected, it is not possible to know the subpopulation that doesn't belong to the population. It is then necessary to use Student test by comparing subpopulations two by two. The main objective of these statistical tests is to provide the best synthetic information about the characteristics of the population. For a given population, one can determine the probabilistic distribution that fits better the observed data. We have used the parametric Student test [28] by comparing the mean 
values and we considered a significance level $\varepsilon=0.05$. The tests were carried out using the software XLSTAT [30].

\subsubsection{Identification of mean values}

For a Student test, two conditions are necessary: the two compared samples must satisfy the Gaussian distribution, this condition is very often satisfied, and the $2^{\text {nd }}$ condition is that the two samples must have the same variance [28]. In our case, both conditions have been satisfied and the Student test has been perfomed. It leads to rejection results in some cases Table 4.

\begin{tabular}{|c|c|c|c|c|}
\cline { 2 - 4 } \multicolumn{2}{c|}{} & \multicolumn{3}{c|}{ TEST RESULTS FOR : } \\
\hline Specimen size & Test between batches & Density & Maximum compressive strength & Young's modulus \\
\hline \multirow{2}{*}{$11 \times 22 c m$} & I and II & not reject & reject & not reject \\
\cline { 2 - 5 } & III and IV & reject & reject & not reject \\
\hline \multirow{2}{*}{$\mathbf{1 6 \times 3 2 c m}$} & I and II & not reject & not reject & not reject \\
\cline { 2 - 5 } & III and IV & reject & reject & \\
\hline
\end{tabular}

Table 4: Student test for batches in both specimen sizes

Consequently it is not possible to combine samples into one population for statistically meaningful size (i.e. statistical analysis requires a minimum number of samples to get acceptable error; the required sample size depends on the statistical property or test to be applied, e.g. mean, standard deviation, density function fitting, etc.). In order to assess the dispersion of data we propose to adjust the sample mean values with respect to the reference mean; this leads to shift the whole probability distributions, such that their mean values become centered on the same reference point. It is important to note that this adjustment is only applied to characterize the sample standard deviation and distribution type, but not to determine the mean values. By applying this approach, Student's test results for all samples are not rejected. For more clarity, the approach is detailed below.

Consider two given samples $\mathrm{X}=\left\{\mathrm{x}_{1} ; \mathrm{x}_{2} ; \ldots ; \mathrm{x}_{\mathrm{i}}\right\}$ and $\mathrm{Y}=\left\{\mathrm{y}_{1} ; \mathrm{y}_{2} ; \ldots ; \mathrm{y}_{\mathrm{i}}\right\}$; their respective mean values $\overline{\mathrm{X}}$ and $\overline{\mathrm{Y}}$; if one wants to adjust the mean value of $\mathrm{Y}$ to the mean value of $\mathrm{X}$, then one has to proceed as following: calculate the adjusted mean value $\overline{Y^{\prime}}$ by using the formula: 


$$
\overline{Y^{\prime}}=\frac{1}{n} \sum_{i=1}^{n}\left[y_{i}+(\bar{X}-\bar{Y})\right]
$$

If the above formula in (3) is developed, it comes that: $\overline{Y^{\prime}}=\bar{Y}+\bar{X}-\bar{Y}$ and finally gives: $\overline{Y^{\prime}}=\bar{X}$, but for this time with variables of $\mathrm{Y}^{\prime}=\left\{\mathrm{y}_{1}^{\prime} ; \mathrm{y}_{2}^{\prime} ; \ldots ; \mathrm{y} ; \mathrm{y}_{\mathrm{n}}^{\prime}\right\}$ which are different of those of $\mathrm{X}=\left\{\mathrm{x}_{1} ; \mathrm{x}_{2} ; \ldots ; \mathrm{x}_{\mathrm{m}}\right\}$ and $\mathrm{Y}=\left\{\mathrm{y}_{1} ; \mathrm{y}_{2} ; \ldots ; \mathrm{y}_{\mathrm{n}}\right\}$ respecively. This approach leads to two different samples having the same mean value; hence it allows combining both samples for scatter and goodness-of-fit analyses.

\section{Results and Discussions}

By considering the testing laboratory, the batch, the hemp shiv type and the specimen size, the studied properties are: density, compressive strength and Young's modulus. In order to simplify the notations, the following abbreviations are used: MV for the Mean Value, SD for the Standard Deviation, COV for the Coefficient Of Variation and CV for the Characteristic Value.

\subsection{Repeatability of the results between testing laboratory}

As seen, the density, the compressive strength and the Young's modulus may vary according to many parameters such as: compaction energy [9,10], measuring method [11] and hemp shiv type [12]. In this section, analyses for results in Table 5 and Table 6 focus on the impact of testing laboratories. 


\begin{tabular}{|c|c|c|c|c|c|c|c|c|c|c|c|c|}
\hline \multirow[b]{2}{*}{ LAB NAME } & \multicolumn{4}{|c|}{ DENSITY (kg/m³) } & \multicolumn{4}{|c|}{ COMPRESSIVE STRENGTH (MPa) } & \multicolumn{4}{|c|}{ YOUNG'S MODULUS (MPa) } \\
\hline & MV & SD & $\mathrm{COV}$ & $\mathbf{C V}$ & MV & SD & $\mathrm{COV}$ & $\mathbf{C V}$ & MV & SD & $\mathrm{COV}$ & $\mathbf{C V}$ \\
\hline ALL LAB & 471.22 & 28.28 & 6.00 & 424.84 & 0.45 & 0.05 & 10.69 & 0.37 & 36.86 & 7.08 & 19.22 & 25.24 \\
\hline A & 496.88 & 31.25 & 6.29 & 445.63 & 0.49 & 0.03 & 5.46 & 0.45 & 33.82 & 4.58 & 13.55 & 26.31 \\
\hline B & 476.93 & 17.64 & 3.70 & 448.00 & 0.48 & 0.04 & 8.45 & 0.41 & 40.72 & 5.01 & 12.29 & 32.51 \\
\hline C & 471.44 & 29.14 & 6.18 & 423.65 & 0.44 & 0.03 & 6.73 & 0.39 & & & & \\
\hline $\mathbf{D}$ & 465.95 & 18.47 & 3.96 & 435.65 & 0.42 & 0.06 & 13.87 & 0.32 & 34.16 & 3.43 & 10.05 & 28.53 \\
\hline $\mathbf{E}$ & 468.44 & 29.35 & 6.27 & 420.31 & 0.49 & 0.02 & 4.47 & 0.45 & 40.87 & 8.63 & 21.13 & 26.71 \\
\hline $\mathbf{F}$ & 465.20 & 26.58 & 5.71 & 421.61 & 0.49 & 0.04 & 8.36 & 0.42 & 35.27 & 3.18 & 9.02 & 30.05 \\
\hline G & 453.72 & 12.96 & 2.86 & 432.47 & 0.41 & 0.04 & 9.42 & 0.34 & 35.33 & 5.11 & 14.45 & 26.96 \\
\hline $\mathbf{H}$ & 472.48 & 35.16 & 7.44 & 414.82 & 0.46 & 0.05 & 10.56 & 0.38 & 44.01 & 9.89 & 22.47 & 27.79 \\
\hline I & 452.71 & 12.64 & 2.79 & 431.99 & 0.45 & 0.05 & 10.78 & 0.37 & 36.01 & 5.23 & 14.53 & 27.43 \\
\hline $\mathbf{J}$ & 514.62 & 15.53 & 3.02 & 489.16 & 0.43 & 0.04 & 8.30 & 0.37 & 28.81 & 4.75 & 16.49 & 21.02 \\
\hline
\end{tabular}

Table 5: Density, maximum compressive strength and Young's modulus values per laboratory, specimens $11 \times 22 \mathrm{~cm}$

\begin{tabular}{|c|c|c|c|c|c|c|c|c|c|c|c|c|}
\hline \multirow[b]{2}{*}{ LAB NAME } & \multicolumn{4}{|c|}{ DENSITY $\left(\mathrm{kg} / \mathrm{m}^{3}\right)$} & \multicolumn{4}{|c|}{ COMPRESSIVE STRENGTH (MPa) } & \multicolumn{4}{|c|}{ YOUNG'S MODULUS (MPa) } \\
\hline & MV & SD & COV & $\mathbf{C V}$ & MV & SD & $\mathrm{COV}$ & $\mathbf{C V}$ & MV & SD & $\mathrm{COV}$ & $\mathbf{C V}$ \\
\hline ALL LAB & 443.53 & 29.70 & 6.70 & 394.81 & 0.38 & 0.06 & 16.77 & 0.28 & 35.58 & 4.46 & 12.54 & 28.26 \\
\hline A & 423.41 & 1.96 & 0.46 & 420.20 & 0.32 & 0.02 & 5.07 & 0.29 & 30.97 & 2.28 & 7.35 & 27.24 \\
\hline $\mathbf{F}$ & 495.45 & 8.56 & 1.73 & 481.42 & 0.48 & 0.02 & 4.47 & 0.44 & 39.13 & 3.04 & 7.77 & 34.14 \\
\hline $\mathbf{G}$ & 445.47 & 4.10 & 0.92 & 438.74 & 0.39 & 0.00 & 1.17 & 0.39 & 32.77 & 2.95 & 9.02 & 27.93 \\
\hline I & 420.38 & 2.10 & 0.50 & 416.93 & 0.32 & 0.01 & 4.15 & 0.29 & 39.06 & 3.42 & 8.76 & 33.45 \\
\hline
\end{tabular}

Table 6: Density, maximum compressive strength and Young's modulus values per laboratory, specimens $16 \times 32 \mathrm{~cm}$

\subsubsection{Density}

The analysis of results obtained by different labs shows small variability for a given specimen size; with a COV of $6.0 \%$ and $6.7 \%$ for all labs in both cases small and large specimens 
respectively, as shown in Table 5 and Table 6 . The observed difference in the characteristic values of the density, while comparing both specimen sizes will be discussed in section 4.4 Within each category of a specimen size, the observed results have excellent quality with reference to the accepted limits in Table 3.

\subsubsection{Maximum compressive strength}

For small specimens $11 \mathrm{x} 22 \mathrm{~cm}$, the compressive strength results show values ranging from 0.32 MPa for lab D to $0.45 \mathrm{MPa}$ for labs A and E, as shown in Table 5. In general, there is no considerable variability in the obtained results. The method and machines used give similar results for the characteristic strength with $10.69 \%$ of COV for all labs. In case of large specimen size, the COV is $16.77 \%$ for all labs, as shown in Table 6 ; this high variability leading to poor quality of the strength. For small specimen size, the quality is excellent with average COV close to the accepted limits as given in Table 3.

\subsubsection{Young's modulus}

Results taking into account the impact of testing laboratory on the evaluation of Young's modulus show mean values ranging from 28.81 MPa to 44.01 MPa. In fact, we have two classes of values, one in the interval from $33 \mathrm{MPa}$ to $38 \mathrm{MPa}$, and the other in the interval from 40MPa to $45 \mathrm{MPa}$, the value of lab J looks like an isolated case. For larger specimen size, the results seem to be homogeneous with a maximum COV equal to $9.02 \%$. These results must be analysed carefully as the number of specimens are not statistically large. Two laboratories have high COV values of $22.47 \%$ and $21.13 \%$, leading to a COV for all laboratories equal to $19.22 \%$, (Table 5). With such COV, the results are of poor quality compared to the limits in Table 3 . There is a significant impact of the testing laboratory on the Young's modulus where the obtained results have poor quality, although the obtained results have excellent quality for the compressive strength. This has to be considered carefully, since it is known that there is a strong correlation between the Young's modulus and the compressive strength. The main explanation to this 
observation is the nonlinear behavior of strength-strain curve, because the maximum strength was calculated beyond the linear phase of the curve, as detailed in section 4.5.

\subsection{Repeatability of the results between batches}

Although the batch type is not yet studied in the literature to our knowledge, but this parameter may influence the results as shown in Table 7.

\begin{tabular}{lcccc|cccc} 
& \multicolumn{3}{c}{ COMPRESSIVE STRENGTH (MPa) } & \multicolumn{3}{c}{ YOUNG'S MODULUS (MPa) } \\
\hline BATCH TYPE & MV & SD & COV & CV & MV & SD & COV & CV \\
\hline I. (11x22cm) & 0.41 & 0.04 & 9.78 & 0.35 & 30.46 & 3.81 & 12.52 & 24.21 \\
II. (11x22cm) & 0.47 & 0.04 & 8.18 & 0.41 & 33.35 & 3.85 & 11.53 & 27.04 \\
III. (11x22cm) & 0.44 & 0.05 & 10.93 & 0.36 & 38.04 & 4.54 & 11.94 & 30.59 \\
IV. (11x22cm) & 0.48 & 0.04 & 8.16 & 0.42 & 44.07 & 7.46 & 16.93 & 31.84 \\
& & & & & & & & \\
I. (16x32cm) & 0.32 & 0.01 & 4.15 & 0.29 & 39.06 & 3.42 & 8.76 & 33.45 \\
II. (16x32cm) & 0.32 & 0.02 & 5.07 & 0.29 & 30.97 & 2.28 & 7.35 & 27.24 \\
III. (16x32cm) & 0.39 & 0.00 & 1.17 & 0.39 & 32.77 & 2.95 & 9.02 & 27.93 \\
IV. (16x32cm) & 0.47 & 0.02 & 4.51 & 0.44 & 39.13 & 3.04 & 7.77 & 34.14 \\
\hline
\end{tabular}

Table 7: Maximum compressive strength and Young's modulus values per batch, specimes 11x22cm and $16 \times 32 \mathrm{~cm}$

\subsubsection{Maximum compressive strength}

The results for compressive strength show that the values for batch IV are higher for both specimen sizes than is the case for Young's modulus. Batches from S2 seem to have high values as shown in Table 7 . This trend is analyzed in section 4.3 where the impact for both shives is studied. As it will be discussed in the next section for the Young's modulus, the compressive strength shows also some variability for different batches, therefore the mixture in different batches must be carefully performed.

\subsubsection{Young's modulus}

Mean values for Young's modulus increase form Batch I with 30.46 MPa to Batch IV with 44.07 MPa as given,Table 7. There is no explanation for this observed trend. However, even with this 
trend, it is clear that batches from the same shiv have comparable results. In batch IV, the COV equal to $16.93 \%$ is greater than other batches, as this one had been manufactured the lastest, maybe the operators did not maintain the same conditions (e.g. compaction energy...) since the beginning up to the end. As this trend is not the same case for large specimens, the justification given above is not necessarily true. For both cases (small and large specimen sizes), an average quality is observed, with respect to limits in Table 3 . This means that the bach does not have a great impact on the results, but sometime it may cause variability, as it is the case of batch IV. Therefore, it is necessary to be careful when mixture is done in different batches.

\subsection{Repeatability of the results for different hemp shiv types}

Arnaud and Gourlay [12] studied the impact of hemp shiv; they concluded that the use of smaller shiv results in concretes whose higher mechanical properties at long term. Nguyen [10] compared two shives one pure another containg fibers; as conclusion to its study there was no big difference on their mechanical properties. In our study, some differences have been observed, according to the results given in Table 8.

\begin{tabular}{|c|c|c|c|c|c|c|c|c|c|c|c|c|}
\hline \multirow[b]{2}{*}{ HEM PSHIV } & \multicolumn{4}{|c|}{ DENSITY $\left(\mathrm{kg} / \mathrm{m}^{3}\right)$} & \multicolumn{4}{|c|}{ COMPRESSIVE STRENGTH (MPa) } & \multicolumn{4}{|c|}{ YOUNG'S MODULUS } \\
\hline & MV & SD & COV & $\mathbf{C V}$ & MV & SD & $\mathrm{COV}$ & $\mathbf{C V}$ & MV & SD & COV & $\mathbf{C V}$ \\
\hline S2 (11x22cm) & 488.88 & 23.11 & 4.73 & 450.97 & 0.46 & 0.05 & 10.38 & 0.38 & 43.45 & 6.72 & 15.47 & 32.43 \\
\hline $\mathrm{S} 1(11 \times 22 \mathrm{~cm})$ & 451.61 & 19.17 & 4.25 & 420.16 & 0.44 & 0.05 & 10.79 & 0.37 & 31.86 & 3.14 & 9.87 & 26.71 \\
\hline $\mathrm{S} 2(16 \times 32 \mathrm{~cm})$ & 469.78 & 27.08 & 5.76 & 425.38 & 0.43 & 0.05 & 10.58 & 0.36 & 32.77 & 2.95 & 9.02 & 27.93 \\
\hline $\mathrm{S} 1(16 \times 32 \mathrm{~cm})$ & 422.10 & 2.51 & 0.60 & 417.98 & 0.32 & 0.01 & 4.00 & 0.30 & 30.97 & 2.28 & 7.35 & 27.24 \\
\hline
\end{tabular}

Table 8: Density, maximum compressive strength and Young modulus values per hemp shiv

\subsubsection{Density}

If we compare both hemp shives in terms of density, we observe slight difference between the obtained densities, even with the specimen size. We obtain $420.16 \mathrm{~kg} / \mathrm{m} 3$ and $450.97 \mathrm{~kg} / \mathrm{m}^{3}$ with $417.98 \mathrm{~kg} / \mathrm{m}^{3}$ and $425.38 \mathrm{~kg} / \mathrm{m}^{3}$ characteristic values for S1 and S2 in both small and large specimen sizes respectively as shown in Table 8. Large values have been observed for S2, which is consistent with the drying kinetics. 


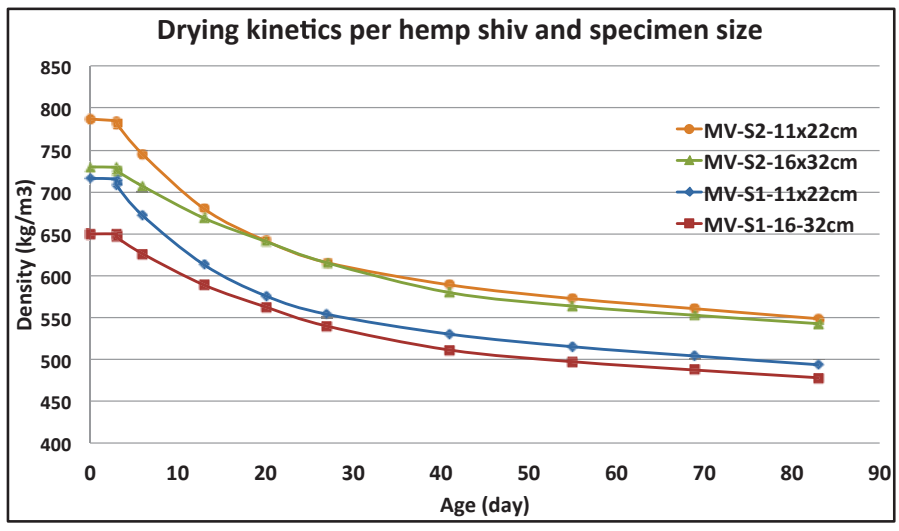

Figure 5: Drying kinetics per hemp shiv and specimen size

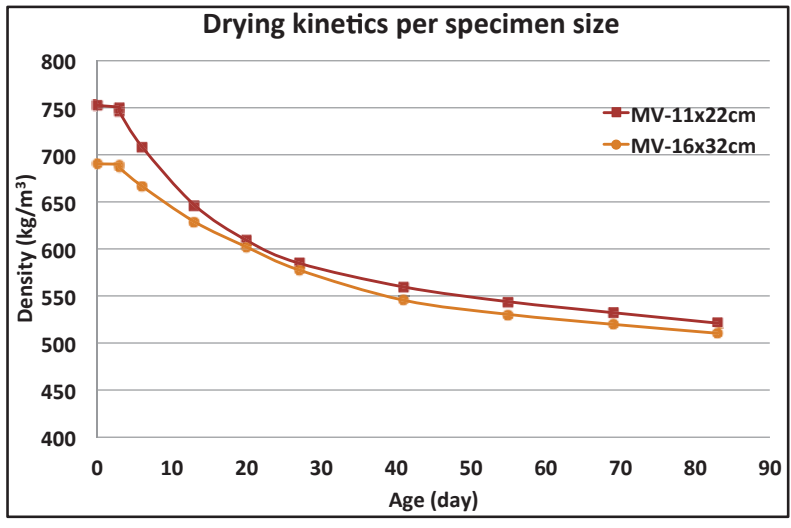

Figure 6: Drying kinetics per specimen size

According to the drying kinetics in Figure 5, it appears that the drying is only affected by the specimen size, which seems normal, because they dry faster since they have a greater specific area than larger specimens. On the other hand, a difference in fresh density is also observed depending on both specimen sizes and hemp shiv types. Small specimens have a higher fresh density than the large specimen, which could be explained by a greater compaction (same "compaction energy" applied by the operator on a smaller area). The specimens made from S2 have a higher fresh density than those from S1, which means that, they were more compacted. The initial water content measured are $10,18 \%$ and $11,12 \%$ for S1 and S2 respectively. This difference in initial water content between S1 and S2 confirm our results. As the water content of the S2 was more important than in S1, the initial absorption of water were reduced (which is the case according to results in Figure 1) and S2 was more easily compacted which explain the high value for fresh density.

\subsubsection{Maximum compressive strength}

The observed compressive strength results are 0.38 MPa and 0.37 MPa for small specimen size; with $0.36 \mathrm{MPa}$ and $0.30 \mathrm{MPa}$ for large specimen size both for S2 and S1, respectively. The maximum strength values for S2 are greater than for S1; this trend is the same for Young's modulus. 


\subsubsection{Young's modulus}

For both specimen sizes, results show that, Young's modulus values for S2 are greater than for S1 values. We also have a high variability for S2 with a COV equal to $15.47 \%$. This is probably due to the fact that batch IV is for S2 and as shown in the previous section, there is a high variability within this batch.

With respect to the type of shiv, in both cases of Young's modulus and compressive strength: these differences can be explained by the fact that, since S2 has a small specific area $13187 \mathrm{~mm}^{2}$, versus $13913 \mathrm{~mm}^{2}$ for $\mathrm{S} 1$, the hemp particles are better coated by the binder during the mixing process of the concrete, which may explain this better mechanical properties of the hemp concretes made from S2. This remark is similar to the results obtained by Arnaud [12] where he remarked that after 4 months, the finer hemp particles gave better mechanical properties than longer hemp particles. This difference may be also justified by the fact that the initial water absorption of S2 is $146 \%$ and for S1 is $212 \%$. This means that S1 absorbs a lot of mixing water and this results in a dry mixture, leading to poor mechanical properties. To avoid this problem, shiv particles may be wetted before the mixing process.

\subsection{Repeatability of the results with respect to specimen sizes}

\subsubsection{Density}

Although the results for each specimen size are not varying too much, density characteristic values obtained for both sizes are $424.84 \mathrm{~kg} / \mathrm{m}^{3}$ and $394.81 \mathrm{~kg} / \mathrm{m}^{3}$ for small and big size respectively, (Table 5 and Table 6). Unlike to what is observed in the case of the maximum compressive strength, there is no difference for the COV values, as discussed in 4.3.1, there are always great values for small specimen size. 


\subsubsection{Maximum compressive strength}

Considering the results obtained for the characteristic values 0.37 MPa and 0.28 MPa for small and big specimens, respectively (Table 5 and Table 6); the specimen size does not have exactly the same trend for the compressive strength as for Young's modulus. Since there is no big difference for minimum, maximum and mean compressive strength values, then the observed difference for characteristic values is related to the COV values.

\subsubsection{Young's modulus}

Results on the impact of specimen size in the case of Young's modulus show comparable values for the mean and characterstic values, (Table 5 and Table 6). A significant difference is observed for the maximum values with a factor equal to 1.32 .

\subsection{Correlation between mechanical characterstics}

The correlation between cubic root of compressive strength and Young's modulus shows that these two mechanical properties are correlated. According to Hooke's law, the Young's modulus corresponds to the slope calculated in linear stage on the curve strength/ strain. For a given homogeneous material; different samples should give almost the same values of stress and Young's modulus for a given strain. Hence the graph strength/Young's modulus may correspond to a concentrated cloud of points. As in the current study, the maximum strength are obtained around $5 \%$ of strain, the Figure 7 was expected to be a concentrated cloud of points but it is not the case. 


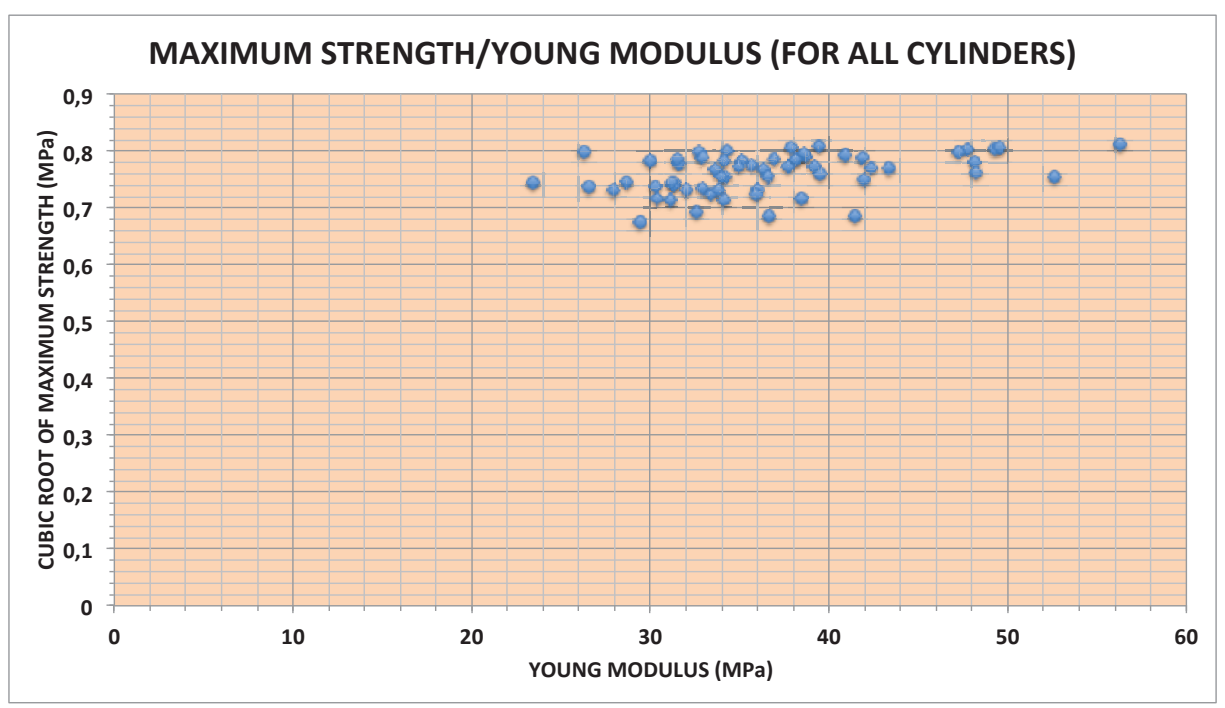

Figure 7: Correlation for cubic root of maximum strength and Young modulus for all specimens

The trend observed in Figure 7 shows to what extend the mechanical properties of hemp concrete are sensitive to studied parameters. As explained in section 4.1.3, this may also due to the fact that the maximum compressive strength is calculated beyond the linear phase of the curve. Compressive strength varies from 0.3 MPa to 0.52 MPa. A great amount of values is located between $30 \mathrm{MPa}$ and $40 \mathrm{MPa}$ for Young's modulus. Nevertheless, the cubic root of compressive strength is in general increasing with Young's modulus.

\subsection{Summary of observations}

At one hand, there are more or less considerable variabilities for hemp concrete properties related to the type of parameters considered. The results, seen so far and performed analyses, have significant scatter that is difficult to estimate or to measure. The main source of these dispersions is the interference of different parameters on the observed results.

Moreover, according to the literature review, we have shown the inadequacy of the accuracy and the confidence level to be given to the results in literature. Regarding the characteristic values of this study, they are up to now given with respect to different parameters. A study taking into account all parameters for a unique characterstic value is necessary. This study is proposed in the next section, with the goal of computing the characterstic values for the three properties. 


\subsection{Probability distributions}

In addition to statistical values (mean, standard deviation...) computed in the previous sections of this paper, it is now required to specify the probability distribution that fits properly the experimental data. As a first step, a preliminary statistical analysis has been carried out to test a large number of probability density functions, in order to select the most appropriate candidates. For each batch, and also for grouped batches, the goodness-of-fit tests have been performed with various distributions, in order to determine which distribution fits better the data. Although various types of probability distributions have been considered to fit the experimental results, three distributions are recommended for practical engineering, namely: normal, log-normal and Weibull distributions, which are commonly used in reliability analysis of civil engineering structures [31]. For Weibull distribution it is commonly used in mechanical to describe statistical variation of failure strength of a material [32]; maybe it is not suitable for hemp concrete, in the current study, it is proposed for information, others studies are required to confirm its use. This goodness-of-fit test is conducted separately for the density, the compressive stress and the Young's modulus. However, before performing these tests, it is mandatory to check whether the dispersion is due to the scatter of the population, or due to mixing different populations with different mean values. For this reason, a test has been conducted to verify that the batches belong to only one consistent population, as the undeneath populations have similar mean values; otherwise the goodness-of-fit test results will be insignificant and the batches should be splitted into two or more populations.

\subsubsection{Density}

As explained in section 3.3.3, the statistical tests have been done on different batches. The results given in Table 4 show that it is only possible to combine batches II and I. This leads to have three populations: batches (I\&II), batch III and batch IV. 
As a matter of fact, although batches III and IV come from the same type of hemp shiv S2, the statistical tests showed that they do not belong to the same population, as this hypothesis has been rejected! In order to explore the reasons for this statistical test result, it has been assumed that there could be a laboratory, which disturbs the results in one or both batches. To detect this laboratory, ANOVA test may have been used, but specimens in each lab are not enough (Table 1) to perform a significant test. As result, we conducted comparison tests for both batches by eliminating lab results, one after another. Unfortunately, the test results remained negative. Furthermore, it has been noticed that by eliminating the batch III results for lab G, the test showed that both batches III and IV belong to the same population, with the risk of rejecting the null hypothesis H0, equal to $9.05 \%$. This result let us believe that the impact of lab $\mathrm{G}$ is related to the fact that it is the only laboratory which tested 6 specimens of batch III, while the others had tested 2 or 3 specimens each. For this reason, the statistical test has been conducted by keeping only 5, 4, 3 and 2 specimens among those of lab G, but in vain. As a conclusion both batches are considered as two separate populations.

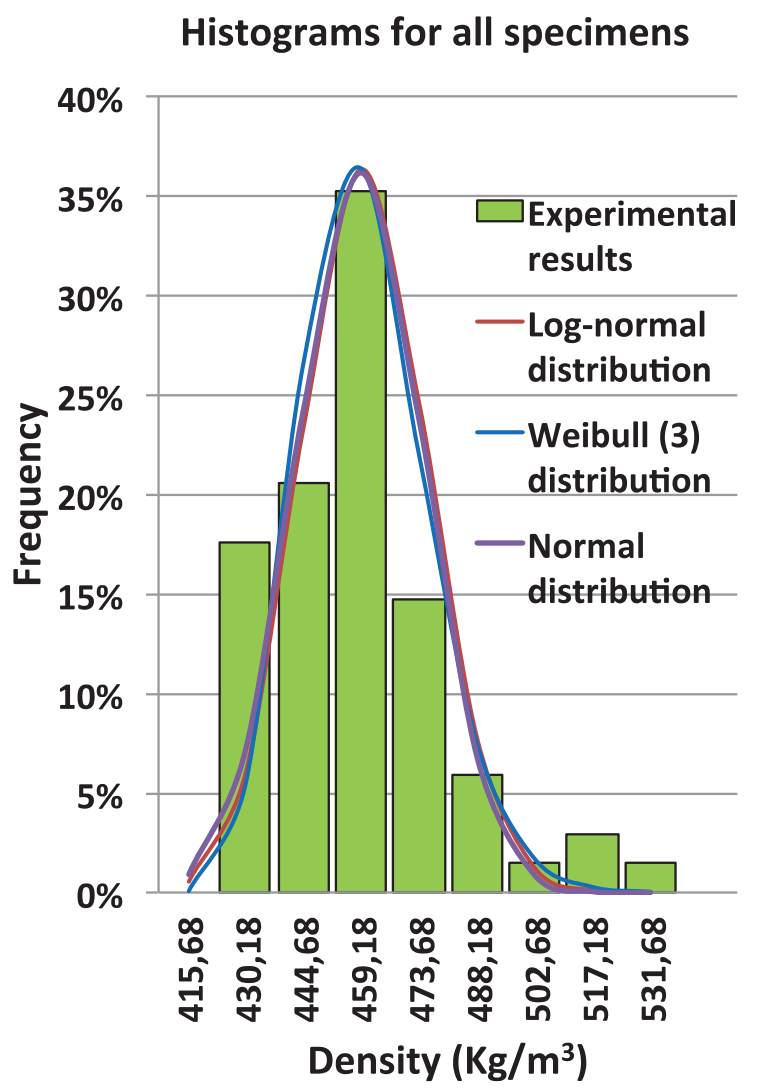


Figure 8 : Probabilistic law for density

\begin{tabular}{|c|c|c|c|c|c|c|c|}
\hline Distribution & \multicolumn{2}{|c|}{ Normal } & \multicolumn{2}{c|}{ Log-normal } & \multicolumn{3}{c|}{ Weibull (3) } \\
\hline \multirow{2}{*}{ parameters } & $\mu$ & $\sigma$ & $\mu$ & $\Sigma$ & $\kappa$ & $\lambda$ & $\eta$ \\
\cline { 2 - 7 } & 450.992 & 22.348 & 6.11 & 0.049 & 1.917 & 39.806 & 415.679 \\
\hline $\begin{array}{c}\text { Statistical } \\
\text { moments }\end{array}$ & $(450.992 ; 22.348)$ & $(450.995 ; 21.99)$ & \multicolumn{2}{|c|}{$(451.207 ; 22.236)$} \\
$(\boldsymbol{\mu} ; \boldsymbol{\sigma})$ & & & & & & & \\
\end{tabular}

Table 9: Distribution parameters and statistical moments for material density

As we do not have large number of specimens in each one of the three populations, the characterization of the coefficient of variation can be carried out by scaling the experimental result of each specimen using the mean value of the population corresponding to batch I. The approach described in section 3.3.3.1 is therefore applied to scale the mean values, in order to get appropriate representation of the dispersion. The obtained population is thus shown to follow properly normal, log-normal and three-parameter Weibull distibutions, while logistic and GEV provide also good fitting. For the considered distributions,

Figure 8 shows how the density functions fit the experimental data and Table 9 indicates their statistical moments.

\subsubsection{Maximum compressive strength}

Regarding the maximum compressive strength, the statistical tests have been performed in order to determine whether we can consider only one population or not. All test results were negative for both specimen sizes and batch parameters, except batch I and II with large specimen dimension, as shown in Table 4. In other words, the Student's tests have led to 7 different populations, which should then be fitted by normal, log-normal and logistic distributions. 


\begin{tabular}{|c|c|c|c|c|c|c|c|}
\hline Distributions & \multicolumn{2}{|c|}{ Normal } & \multicolumn{2}{|c|}{$\begin{array}{c}\text { Log- } \\
\text { normal }\end{array}$} & \multicolumn{3}{|c|}{ Weibull (3) } \\
\hline \multirow[b]{2}{*}{ Parameters } & $\mu$ & $\sigma$ & $\mu$ & $\Sigma$ & $\kappa$ & $\lambda$ & $\eta$ \\
\hline & 0.397 & 0.052 & $\begin{array}{c}- \\
0.93\end{array}$ & 0.135 & 2.3 & 0.115 & 0.295 \\
\hline $\begin{array}{c}\text { Statistical } \\
\text { moments ( } \mu \text {; } \\
\sigma)\end{array}$ & \multicolumn{2}{|c|}{$(0.397 ; 0.055)$} & \multicolumn{2}{|c|}{$\begin{array}{l}(0.397 ; \\
0.055)\end{array}$} & \multicolumn{3}{|c|}{$(0.397 ; 0.045)$} \\
\hline
\end{tabular}

Table 10: Distribution parameters and statistical moments for the maximum compressive strength

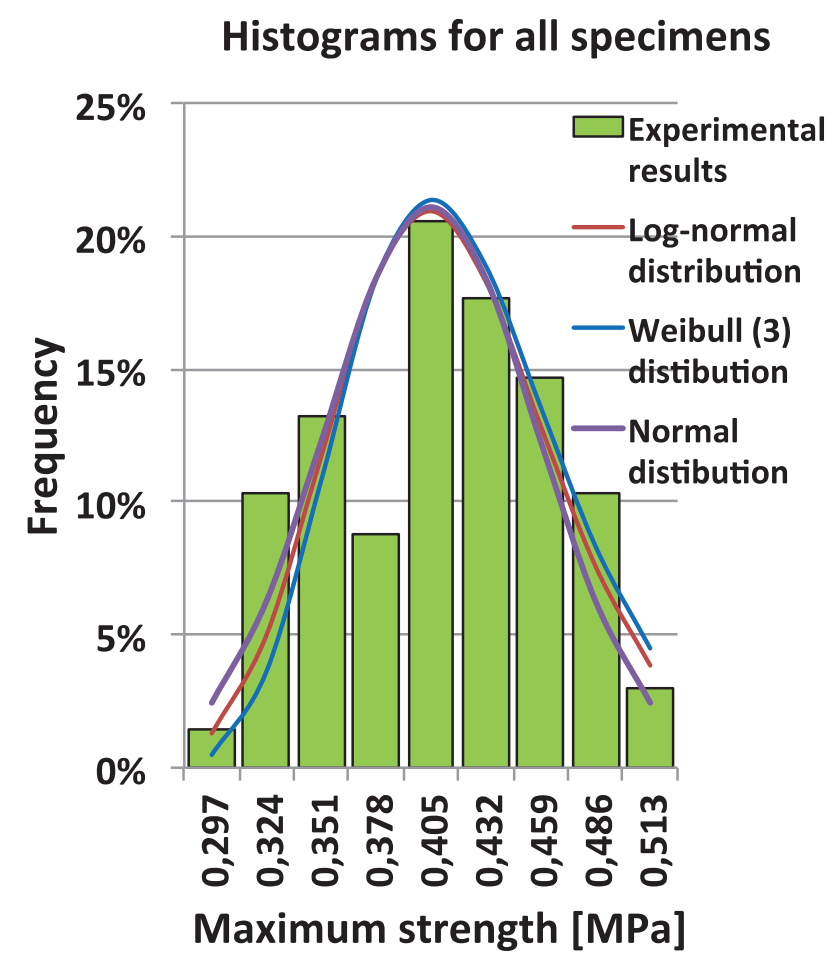

Figure 9: Probabilistic law distributions for maximum strength

In order to analyze the scatter of experimental results, the scaling procedure described in section 3.3.3.1 is applied to get a unique scaled population. The experimental results can then be fitted to 
normal, lognormal and Weibull distributions, Figure 9, with the statistical moments given in Table 10.

\subsubsection{Young's modulus}

The Young's modulus is calculated by the method explained in section 3.3.1. The experimental results obtained by this method are subjected to Student's test, and the results are given in Table 4. As the tests are rejected in the case of small specimen for batches III and IV, we used the approach described in section 3.3.3.1 to scale the results. The fitting of probability distributions is shown in Figure 10 with their statistical moments in Table 11.

The trend of the experimental results indicates the existence of two sub-populations: a first subpopulation is located at the mean value of $27.75 \mathrm{MPa}$ and a second subpopulation has a mean of $35.75 \mathrm{MPa}$, as shown in Figure 10 . This trend may be due to the fact that we have two specimen sizes. The same trend was also observed in 4.4 .3 where a significant difference is observed for the maximum values with a factor equal to 1.32 . 


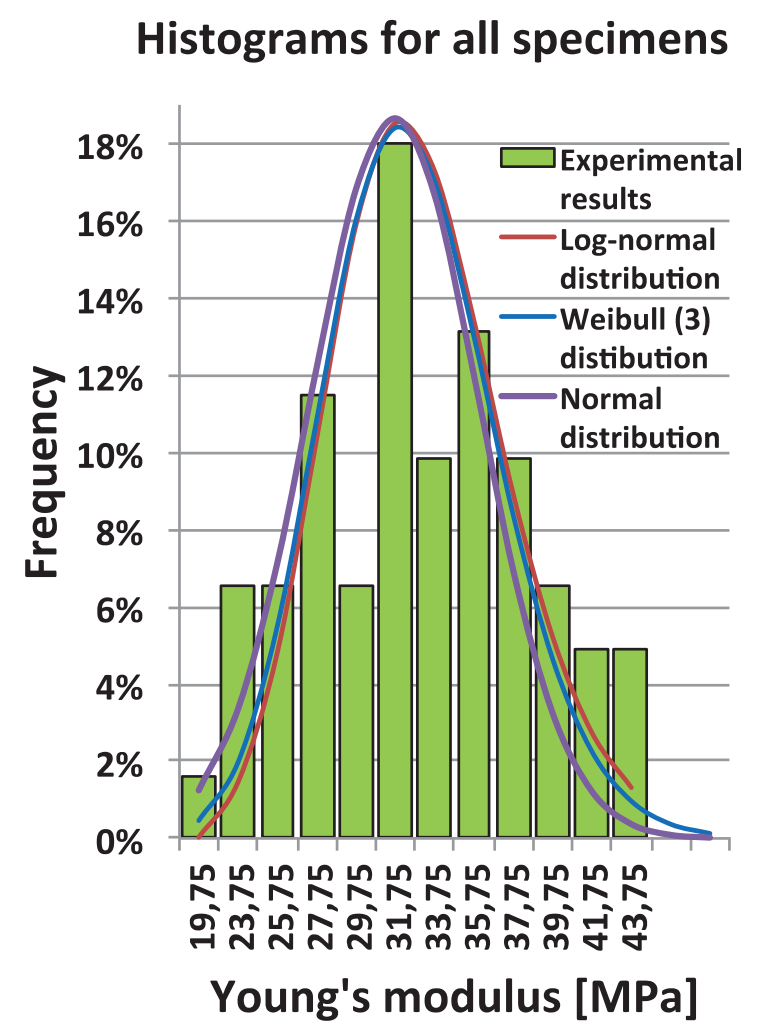

Figure 10: Probabilistic law distributions for Young's modulus

\begin{tabular}{|c|c|c|c|c|c|c|c|}
\hline Distributions & \multicolumn{2}{|c|}{ Normal } & \multicolumn{2}{c|}{ Log-normal } & \multicolumn{3}{c|}{ Weibull (3) } \\
\hline \multirow{2}{*}{ parameters } & $\mu$ & $\sigma$ & $\mu$ & $\Sigma$ & $\kappa$ & $\lambda$ & $\eta$ \\
\cline { 2 - 7 } & 31.874 & 5.669 & 3.445 & 0.185 & 2.76 & 15.868 & 17.751 \\
\hline $\begin{array}{c}\text { Statistical } \\
\text { moments } \\
(\boldsymbol{\mu} ; \boldsymbol{\sigma})\end{array}$ & $(31.874 ; 5.669)$ & $(31.898 ; 5.943)$ & \multicolumn{2}{|c|}{$(31.865 ; 5.694)$} \\
\hline
\end{tabular}

Table 11: Distribution parameters and statistical moments for Young's modulus

\subsection{Proposed characterstic values for studied properties}

As discussed above, it is not possible to consider each parameter separately. Further probabilistic studies could be required to take into account the interaction of all parameters, but this is beyond the scope of the present work. As we have the marginal probability distribution for each 
parameter, we can compute the characterstic values with the formula given in eq (1) with the probability level equal to 5\%. Using the obtained normal distributions, the characteristic values of the three parameters are computed as: 22.5 MPa for the Young's modulus, 0.30 MPa for the compressive strength and $\mathbf{4 1 5} \mathrm{kg} / \mathrm{m}^{3}$ for the density.

\section{Conclusion}

The statistical analysis has been performed for three material properties, namely the density, the compressive strength and the Young's modulus, by taking into account four parameters: testing laboratory, batch type, hemp shiv type and specimen size. The results obtained by different laboratories show that there is an accurate repeatability for compressive strength and dry density. However, the results for Young's modulus are of a large variability, with results varying from excellent to poor quality. The results also showed that there is some variability between different batches, and therefore the mixing procedure must be done with an utmost care. The impact of initial water content on the density has been also highlighted. More initial water content is, less will be the density of the corresponding hemp concrete. It has also been noticed that the hemp with small particle sizes leads to better mechanical properties of hemp concrete.

According to the obtained results, plausible evidence for specimen size effect was observed. However, further investigations should be undertaken in the future on larger number of specimens with different sizes, in order to provide full understanding of the effect of specimen size.

Regarding the statistical analysis, the mean values and standard deviations of the considered batches have been computed and provide consistent results. A statistical procedure has been proposed to assess the scatter and the distribution type of the combined batches. The goodnessof-fit test has shown that the experimental results are in good agreement with the probability distributions: normal, log-normal and Weibull. According to usual recommendations in civil 
engineering, especially in Eurocodes, the log-normal distribution may be suggested to model the considered properties.

This study will be enhanced by ongoing works on separating the statistical contributions of each basic paremeter (batches, hemp shiv...), through the development of Bayesian network approaches. This Bayesian network study may bring useful informations to answer to the remaining questions.

\section{References}

[1] V. Nozahiv, S. Amziane, G. Torrent, K. Said. H, De Baynast. Design of green concrete made of plant-derived aggregates and a pumice-lime binder, 2011.

[2] V. Nozahic, S. Amziane, Influence of sunflower aggreagtes surface treatments on physical properties and adhesion with a mineral binder, 2012.

[3] Paulien de Bruijn, Peter Johansson. Moisture fixation and thermal properties of limehempconcrete, 2013.

[4] Paulien Brigitte de Bruijn, Knut-Håkan Jeppsson, Kenneth Sandin, Christer Nilasson. Mechanical properties of lime-hemp concrete containg shives and fibres, 2009.

[5] S. Elfordy, F. Lucas, F. Tancret, Y. Scudeller, L. Goudet. Mechanical and thermal properties of lime and hemp concrete (« hempcrete ») manufactured by a projection process.

[6] A. Sellami, M. Merzoud, S. Amziane. Improvement of mechanicalproperties of green concrete by treatment of the vegetals fibers, 2013.

[7] H. Binici, M. Eken, M. Dolaz, O. Aksogan, M. Kara. An environmentally friendly thermal insulation material from sunflower stalk, textile waste and stubble fibres, 2013.

[8] F. Collet, J. Chamoin, S. Pretot, C. Lanos, comparison of the hygric behaviour of three hemp concretes, 2013. 
[9] V. Cerezo, Propriétés mécaniques, thermiques et acoustiques d'un matériau à base de particules végétales : approche expérimentale et modélisation théorique. Ph.D thesis, at Institut National des Sciences Appliquées de Lyon, 2005.

[10] T.T. Nguyen, Contribution à l'étude de la formulation et du procédé de fabrication d'éléments de construction en béton de chanvre. Ph.D thesis, at Université Bretagne Sud, 2009.

[11] F. Collet, Caractérisation hydrique et thermique de matériaux de génie civil à faibles impacts environnementaux. Ph.D thesis, at Institut National des Sciences Appliquées de Rennes, 2004.

[12] L. Arnaud, E. Gourlay, experimental study of parameters influencing mechanical properties of hemp concretes. Construction and Building Materials, vol. 28. 2012. P. 50-56.

[13] T.T. Nguyen, Picandet V., Amziane S., Baley C. Influence of compactness and hemp hurd characteristics on the mechanical properties of lime and concrete. Eur J Environ Civil Eng 2009 ; $13: 1039-50$.

[14] P. Mounanga, P. Poullain, G. Bastian, P. Glouannec, H. Khelifi. Influence de la composition et du mode de mise en œuvre sur le développement des propriétés mécaniques du béton de chanvre, AUGC 2009 02/05, page 1 à 11.

[15] F.M Almeida Filho, B.E Barragan, J.R Casas, A.L.H.C EI Debs; Hardened properties of self-compacting concrete - A statistical approach; 2010.

[16] INRA national website, research center of Jouy-en-Josas Internet link: http://w3.jouy.inra.fr/unites/miaj/public/matrisq/jbdenis/notes/notions/notions.html\#stat, visted on $3^{\text {rd }}$ April 2014.

[17] S. Amziane, F. Collet, M. Lawrence, C. Magniont, V. Picandet; Round Robin Test for hemp shiv characterization: committee report of TC-236 bio-based building materials part I: evaluation of initial water content and water absorption. [STAR of TC-BBM 236-Rilem publication].

[18] S. Amziane, F. Collet, M. Lawrence, C. Magniont, V. Picandet; Round Robin Test for hemp shiv characterisation: committee report of TC-236 bio-based building materials partII: bulk 
density and particle size distribution. [STAR of TC-BBM 236-Rilem publication].

[19] AFNOR, Norme NF EN 933-2 - Essais pour déterminer les caractéristiques géométriques des granulats - Partie 2: détermination de la granularité - Tamis de contrôle, dimensions nominales des ouvertures, AFNOR ; Mai 1996.

[20] C. Igathinathane, L.O. Pordesimo, E.P. Columbus, W.D Batcheloret, S. Sokhansanj, « Sieveless particle size distribution analysis of particulate materials through computer vision. » Computers and Electronics in Agriculture, vol.66, 2009, p.147-158.

[21] V. Nozahic, Vers une nouvelle démarche de conception des bétons de végétaux lignocellulosiques basée sur la compréhension de l'interface liant/végétal. Ph.D thesis, at Université Blaise Pascal, 2012.

[22] A.M Nazar, F.A Silva and J.J Ammann.«Image processing for particle characterization». Materials characterization, vol. 36, 1999, p.165-173.

[23] Tiago Ferreira; Wayne Rasband « ImageJ user guide: IJ 1.46r » available on: http://imagej.nih.gov/ij/docs/guide/user-guide.pdf

[24] S. Amziane, L. Arnaud, «Bio-aggregate-based Building Materials. Applications to hemp concretes. » Civil Engineering and geomechanics series, 2013.

[25] Construire en chanvre : règles professionnelles d'exécution. Paris : Société d'édutions du bâtiment et de travaux publics, 2009.

[26] Borel S., Reiffsteck P. «caractérisations de la déformabilité des sols au moyen d'essais en place »; Géotechniques et risques naturels, 2006.

[27] Damien Ricotier et Dominique Vié; Dimensionnement des structures en béton selon l'Eurocode 2 De la descente des charges aux plans de ferraillage, 2012.

[28] Paul JAFFARD, initiation aux méthodes de la statistique et du calcul des probabilités.Paris, MASSON, 1996.

[29] Roger Journeaux. Traitement des Mesures: Interprétation, Modélisation, Outil Statistique. Paris : Ellipses, 2009. 
[30] Software XLSTAT, 1995-2014 Addinsoft, available on website: www.xlstat.com

[31] R. Atadero, L. Lee, V. M. Karbhari. «Consideration of material variability in reliability analysis of FRP strengthened bridge decks » Composite structure 70 (2005) 430-443.

[32] ANDERSON, Ted L. Fracture mechanics: fundamentals and applications. CRC press, 2005. 